Original Research Article

\title{
Second year medical students' feedback on teaching-learning methodologies and evaluation methods in Pharmacology: a questionnaire based study
}

\author{
Vijaya Chandra Reddy Konda*, G. Bhanu Prakash, K. R. Subash, K. Umamaheswara Rao
}

Department of Pharmacology, Sri Venkateswara Institute of Medical Sciences, Sri Padmavathi Medical College for Women, Tirupati, Andhra Pradesh, India

Received: 28 April 2017

Accepted: 08 May 2017

*Correspondence to: Dr. Vijaya Chandra Reddy Konda,

Email: vijayachandrareddy@ gmail.com

Copyright: (C) the author(s), publisher and licensee Medip Academy. This is an openaccess article distributed under the terms of the Creative Commons Attribution NonCommercial License, which permits unrestricted noncommercial use, distribution, and reproduction in any medium, provided the original work is properly cited.

\begin{abstract}
Background: Pharmacology enables medical students with the art of rational prescriptions of drugs. It is one of the rapidly evolving subjects in medical sciences. The purpose of the study was to assess whether teaching-learning methodologies and evaluation methods are supporting the curriculum goals and what modifications can be made for the benefit of medical students.

Methods: After approval by the Institutional Ethics Committee the study was carried out in January-February 2017. A total of 128 students of 2nd MBBS were administered a pre-validated questionnaire after explaining the purpose of the study. Descriptive statistics were used for analysis of data. Frequency was expressed as percentage.

Results: A total response rate of $93.75 \%$ was observed. Most of the students mentioned cardiovascular system $(20.8 \%)$ as the most interesting topic. $78.3 \%$ preferred teaching by use of combination of both audio-visual aids and chalk and board. Majority of the students rated practical classes as similar to theory (34.2\%). 91.7\% students mentioned that seminars are useful to them. $95 \%$ of students are interested in continuation of the integrated classes conducted at the end of each chapter. $98.3 \%$ of students for written tests and $90 \%$ for viva voce responded positively for the need of such periodic evaluation in addition to university prescribed evaluations. $95 \%$ students mentioned that field visits helps them in better understanding of pharmacology.

Conclusions: The present study helped us to elicit student preferences regarding teaching and evaluation methods in pharmacology. Implementation of the same would be helpful for better outcome of students.
\end{abstract}

Keywords: Curriculum, Integrated teaching, Feedback, Pharmacology, Seminars

\section{INTRODUCTION}

Therapeutic outcome and safety of patients depend largely on rational prescribing of medicines. Pharmacology is the fundamental subject in the field of medicine that enables medical students with the art of rational prescriptions of drugs. ${ }^{1}$ It is one of the rapidly evolving subjects in medical sciences. In order to keep pace with the changes being made in the subject by many innovations, the teaching methodologies and evaluation methods also need to be constantly kept under review.
Teaching methods in medical education evolved rapidly in the past three decades. Many reforms are being made in pharmacology curricula and teaching-learning methodologies to best suit medical students' learning. There is a shift from mere didactic lectures to usage of audio-visual aid based lectures and computer-based learning. The relevance of conventional pharmacology practical exercises like dispensing pharmacy and experimental pharmacology was always questioned and criticized. ${ }^{2}$ Regulations by the Medical Council of India resulted in more emphasis being laid on clinical aspects which led to incorporation of clinical pharmacology 
exercises, problem-based learning, case-based learning, integrated teaching, microteaching, student seminars, pharmaceutical industry visits into the curriculum. ${ }^{3}$

There is growing awareness that students' views and opinions are most valuable in assessing the effectiveness of teaching methods. ${ }^{4}$ Feedback from students serve as an effective tool in designing and developing teaching methodologies and evaluation methods. Implementation of suggestions obtained from students in the form of feedback results in improvement of their academic performance. ${ }^{5}$ The first batch of MBBS students from Sri Venkateswara Institute of Medical Sciences (SVIMS), Sri Padmavathi Medical College for Women (SPMCW) appeared for their $2^{\text {nd }}$ MBBS examinations in February 2017. The present study is a step to obtain feedback from students about teaching-learning methodologies and evaluation methods so that necessary modifications can be done for better outcomes in students.

\section{METHODS}

This cross-sectional questionnaire based study involved second year medical students from $5^{\text {th }}$ semester studying in Sri Venkateswara Institute of Medical Sciences, Sri Padmavathi Medical College for Women, Tirupati, Andhra Pradesh. The protocol was approved by Institutional Ethics Committee of Sri Venkateswara Institute of Medical Sciences (IEC No. 580, dated 14/11/2016). The study was conducted in JanuaryFebruary 2017. Students who have consented to participate and present on the day of the study were included in the study. Students who have not given their consent and absent on the day of the study were excluded from the study.

The questionnaire contained 25 questions and was adapted from the previous studies that assessed feedback of second year medical students on teaching-learning methodology and evaluation methods in pharmacology. 6,7 A few modifications were done in the questionnaire to best fit with reference to curriculum that is being followed in our institute. The questionnaire included questions on three main categories, i.e., teaching-learning methodology, evaluation methods and general questions. The questionnaire had both open-ended and close-ended questions. Each question had 2 to 10 options and the students were asked to mark their responses as per the instructions given in the question. Questionnaire validation was done by a pilot study on 15 students to review the questionnaire and to determine whether the questionnaire measured what it was designed to measure. Descriptive statistics was used for analysis of data and results were expressed as percentage

\section{RESULTS}

Out of the 128 students to whom questionnaire was administered, 120 completed questionnaires were accepted. 8 incomplete questionnaires were discarded.
The total response rate of $93.75 \%$ was observed. $35.8 \%$ of the students came to know about the subject pharmacology before joining MBBS, 34.2\% knew about it in their $1^{\text {st }}$ MBBS and the remaining $30 \%$ of the students were unaware of the subject till their entry into $2^{\text {nd }}$ MBBS. When asked about their opinion about pharmacology subject, $34.2 \%$ mentioned that it is "very useful, practically important and interesting". $28.3 \%$ mentioned as "useful and interesting" and $25.8 \%$ mentioned as "useful but boring". It was specified by $11.7 \%$ students that the subject is interesting and important but difficult to remember.

As much as $39.2 \%$ students mentioned that they prefer studying pharmacology by text books only, $8.3 \%$ by selfprepared notes, $2.5 \%$ by teacher's class notes and majority $50 \%$ by combination of all. When asked about their pattern of studying pharmacology, 35.8\% mentioned that they study regularly because of tests/viva and interactive classes, $13.3 \%$ mentioned that they study regularly for gaining more knowledge and $5.8 \%$ study regularly because of interest. $45 \%$ of the students study pharmacology only during tests and exams. $47.5 \%$ students mentioned that their method of learning pharmacology is by the combination of cramming/mugging, grasping the thing and understanding. $39.2 \%$ mentioned that they learn pharmacology by understanding, $7.5 \%$ by grasping the things and the remaining $5.8 \%$ by cramming or mugging the subject. The preferred method for classroom teaching for a majority of $78.3 \%$ students was the use of combination of both audio-visuals aids and chalk and board. $14.2 \%$ preferred only audio-visuals aids and the remaining $7.5 \%$ students preferred only chalk and board method. Most of the students found cardiovascular system $(20.8 \%)$ as the most interesting topic in pharmacology. Responses of students to their most interesting topic is shown in Figure 1.

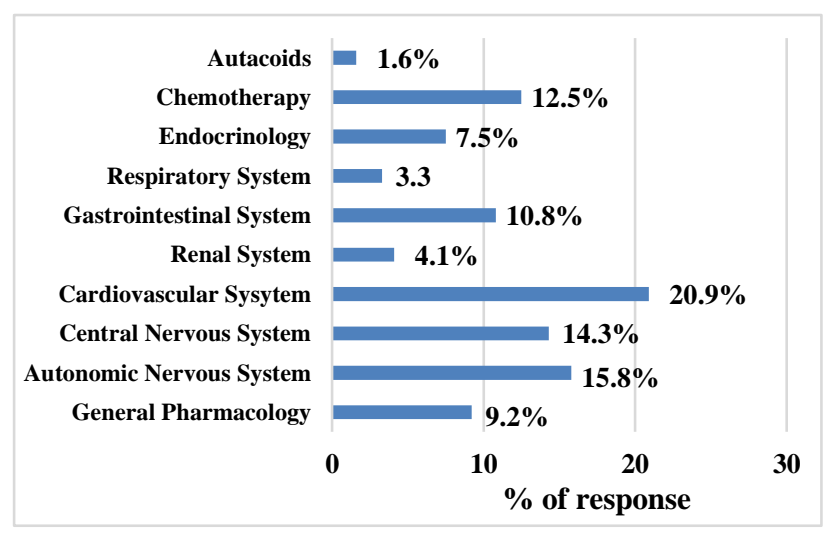

Figure 1: Most interesting topic of students expressed in percentages.

$35.8 \%$ of students mentioned problem based learning and $30 \%$ mentioned prescription writing as their most interesting practical exercises. These were followed by exercises on fixed dose combinations (15\%), criticism of 
prescription (13.3\%) and finally experimental graphs $(5.8 \%)$. In response to the question to rate practical classes compared to theory classes, $35.8 \%$ students mentioned they are "more of theory and less of practicals", $27.5 \%$ students mentioned they are "more of practicals and less of theory", $34.2 \%$ students mentioned they are "similar to theory" and only $2.5 \%$ students responded as "purely practical". Most of the students mentioned that pharmacology should be taught in or after III MBBS also. Among these, 38.3\% students mentioned that there should be only few lectures on newer drugs and recent advancements in therapy, $34.2 \%$ students mentioned that there should be regular lectures on drug therapy in III MBBS, $24.2 \%$ students mentioned that there should be orientation course for few days during internship, $3.3 \%$ students mentioned no need of pharmacology teaching in and after III MBBS. A majority of $74.2 \%$ students mentioned that one and half years is adequate for II MBBS teaching, while $16.7 \%$ students mentioned that one year is sufficient and the remaining 9.2\% mentioned that two years is required for teaching II MBBS subjects. When asked to rate pharmacology in comparison to other MBBS subjects, $32.6 \%$ mentioned it as above all the subjects and $67.4 \%$ mentioned it as average and same as others. Majority of the students, $80.8 \%$ were comfortable in interacting about the subject with pharmacology teachers. Because of varied reasons like fear, lack of confidence and time, the remaining $19.2 \%$ were not comfortable to interact with their teachers.

Feedback on seminars by students revealed that majority of the students, $83.3 \%$ do not come prepared when they are not presenting the seminar. Given an opportunity to volunteer to present the seminar, it was observed that only $54.2 \%$ of the students are willing to present a seminar. The various reasons that prevented students from active participation in seminars in descending order of their responses mentioned are stage fear, lack of indepth understanding of the subject, lack of confidence, unable to manage time because of hectic academic schedule, not comfortable with the use of computers and internet, lack of communication skills, lack of motivation, lack of interest and other specified is afraid of interaction during the seminar and is shown in Figure 2. 91.7\% students felt seminars are helpful to them. It was further mentioned by these students that seminars helped them in better understanding of the subject $(52.7 \%)$, improvement in communication skills $(41.8 \% 0$, enhance confidence to perform better $(54.5 \%)$, motivation to learn (39\%), increase interest towards the subject (49\%).

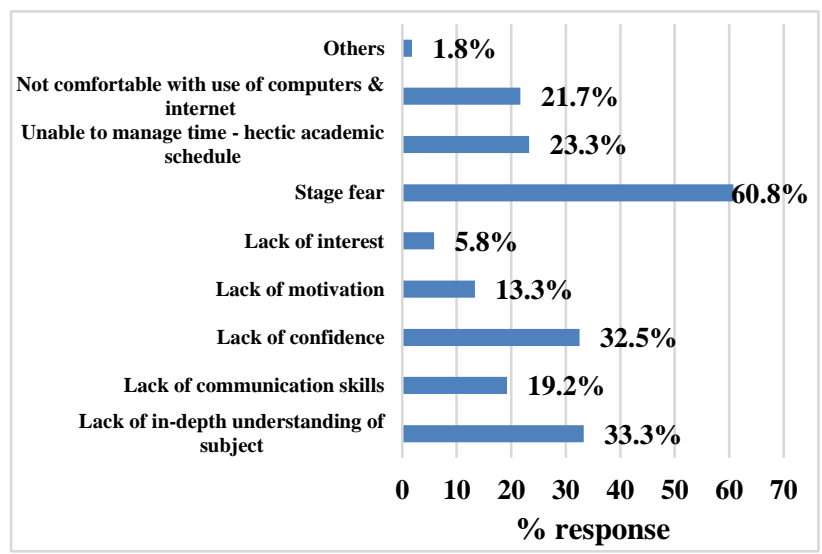

Figure 2: Reasons (in percentages) that prevent students from active participation in seminars.

In the feedback questions regarding the classes taken by concerned clinical speciality at the end of each chapter as part of integration, 95\% students mentioned that it is the appropriate time to exposure students to such integrated sessions in II MBBS, and further expressed their interest in continuation of such integrated sessions. 84.2\% students mentioned that they attended these sessions out of interest. $74.2 \%$ students mentioned that these sessions exposed them to therapeutic applications of drugs, $20.8 \%$ mentioned increased understanding of the subject and the remaining 5\% mentioned they were burdened or stressed with more information. $95 \%$ of the students

In addition to the university prescribed internal evaluations, students were subjected to periodic evaluation in the form of written tests and viva voce. Details of the feedback to such evaluations is given in Table 1. It was mentioned by $95 \%$ of the students that field visits helps in better understanding of pharmacology. Among these, $86.8 \%$ of the students are interested in having visits to all the three pharmaceutical industry, clinical research organization and preclinical testing laboratories.

Table 1: Feedback of periodic evaluation of students in the form of written tests and viva voce in addition to university prescribed internal evaluation (expressed as percentages).

\begin{tabular}{|c|c|c|c|c|c|}
\hline \multirow{2}{*}{$\begin{array}{l}\text { S. } \\
\text { No. }\end{array}$} & \multirow{2}{*}{ Question } & \multicolumn{2}{|c|}{ Written tests } & \multicolumn{2}{|c|}{ Viva voce } \\
\hline & & Yes & No & Yes & No \\
\hline 1 & Is periodic evaluation of students required? & $98.3 \%$ & $1.7 \%$ & $90 \%$ & $10 \%$ \\
\hline 2 & $\begin{array}{l}\text { Does periodic evaluation help you in performing better in internal and } \\
\text { university examinations? }\end{array}$ & $98.3 \%$ & $1.7 \%$ & $90 \%$ & $10 \%$ \\
\hline \multirow{5}{*}{3} & \multicolumn{5}{|c|}{ If yes, to the above questions, at what frequency do you expect to be periodically evaluated? } \\
\hline & (a) At the end of each chapter & $61.9 \%$ & & $55.6 \%$ & \\
\hline & (b) Once in every month & $16.1 \%$ & & $18.5 \%$ & \\
\hline & (c) Once in every two months & $14.4 \%$ & & $20.4 \%$ & \\
\hline & (d) Once in every three months & $7.6 \%$ & & $5.5 \%$ & \\
\hline
\end{tabular}




\section{DISCUSSION}

In the present study many interesting things were observed for necessary modifications in pharmacology teaching to make it more interesting and understandable to students. The results further emphasize the need for reviewing teaching programs from time to time to keep it in pace with the progress made in the subject and various teaching methodologies.

Majority of the students know about pharmacology before entry into II MBBS. However, a group of students were unaware of the subject till their entry into II MBBS, emphasizing the need for conduct of subject orientation program before the students enter into medical education. Though a majority of the students found the subject interesting, about a quarter of the students felt that the subject is boring. Most of the students found cardiovascular system, autonomic nervous system, central nervous system, chemotherapy, gastrointestinal tract and general pharmacology as the most interesting topics in pharmacology whereas endocrine, renal system, respiratory system and autacoids were regarded as less interesting topics in pharmacology. So, these topics need to be more emphasized by including newer teaching learning methodologies to draw attention of the students. The results of this study was almost in consistent with the study conducted by Zaman SU et al. ${ }^{8}$ Pharmacology teaching has conventionally focused on the format of mechanism of action, adverse effects and therapeutic uses of drugs. Modification of pharmacology lectures into a more clinical-oriented format by inclusion of relevant clinical case studies, clinical pharmacology sessions and clinical vignette containing multiple choice questions will be more interesting and helpful for better comprehension by the students. ${ }^{9,10}$

It was observed in this study that the pattern of study by majority of the students was regular because of tests or viva and interactive classes. It implies that the students need a trigger to study on a regular basis. We tried to stimulate students to study regularly by periodically evaluating them in the form of written tests and viva voce apart from university prescribed routine internal assessments. Almost all the students responded positively for the need for such periodic evaluation and further mentioned that these evaluations helped them to perform well in internal assessments and university examinations. The responses by most of the students from this study support the observation of a study done to correlate performance of medical students in internal assessment and final examinations. ${ }^{11}$ Presently students are evaluated by written tests at the end of each chapter and by viva voce once in every three months. Responses by most of the students to implement viva voce also at the end of each chapter has stimulated us to work on the feasibility to implement the same. It was further observed in a pilot study that structured viva voce examination (SVVE) is better and more realistic than traditional viva voce examination (TVVE). SVVE reduces subjectivity of viva, adds to uniformity in assessment and assesses higher domains of learning and communication. Student's feedback was quite encouraging with $83 \%$ overall acceptability and almost $66 \%$ preferred SVVE. ${ }^{12}$ Hence, a great deal of work is to be done to bring about effective implementation of viva voce examinations.

When asked to rate practical classes compared to theory classes it was observed that about $70 \%$ of the students responded by mentioning either practical classes were similar to theory or they were of more of theory and less of practicals. Practical sessions conducted at our institute include prescription writing, problem based learning, prescription audit, spotter identification, rational use of drugs and experimental graphs. One probable reason for such response by students could be due to the ban of most of the experimental pharmacology exercises at the level of under graduate medical education. Though clinically useful exercises were included in the curriculum that best suits to the clinical application of drugs, none of them were able to really induce the sense of typical practicals that make students learn by doing. Hence, a need for the change in practical curriculum is needed. This can be addressed by practical demonstration of various clinical pharmacology practicals like mode of drug administration, drug delivery devices on mannequins; and addition of pharmacovigilance activities like Adverse Drug Reaction (ADR) reporting and filling up of an ADR reporting form into practical curriculum. ${ }^{13}$ Practical exercises can be further strengthened by including simulated experiments in the form of computer assisted learning to teach receptor pharmacology and demonstrate the action of drugs on animal tissues. ${ }^{14}$

Almost all the students mentioned the need for teaching pharmacology in or after $3^{\text {rd }}$ MBBS also. Additionally, findings from another study showed that $73.2 \%$ of the interns suggested the need for implementation of pharmacology teaching in $3^{\text {rd }}$ MBBS apart from that in $2^{\text {nd }}$ MBBS. $^{15}$

Seminars is a small group teaching-learning method in which the participants discuss under the guidance of an expert. In the present study, it was mentioned by many students that they do not come prepared for the seminar when they are not presenting it. Lack of adequate interaction or incentive for active participation results in passive approach by students to these student-led seminars (SLS). There is a need to modify the seminars in the way they are being conducted. Modifications in these seminar sessions in the form of quiz following SLS, patient-oriented problem-solving exercises following SLS, test sessions with SLS, and group discussions and role plays with SLS to make them active process of teaching-learning showed that such modifications created more interest, enthusiasm, and inspiration to learn the topic when compared to traditional SLS. ${ }^{16-19}$ Such modified SLS may be adopted to break the monotony of traditional seminars through active participation, peer interaction and teamwork. 
Integrated teaching is the need of the hour that improves quality of the students resulting in effective diagnosis and better treatment of patients. ${ }^{20}$ The students in our institute were exposed to integrated teaching in the form of lectures by the concerned clinical speciality at the end of each chapter. Integrated teaching-learning (TL) sessions were well appreciated by students and faculty. In view of an overwhelming response from students to these sessions in the form of better understanding and increased exposure to therapeutic applications, we are continuing such teaching modules for the next batch of students also. It was observed that students who are trained with an integrated curriculum, make a more accurate diagnosis than did the students trained in a conventional curriculum. $^{21}$ Effective implementation resulted in improved critical reasoning skills and better understanding of concepts by the students. ${ }^{22,23}$

Most of the students mentioned in the study that field visits to pharmaceutical industry, clinical research organization and preclinical testing laboratories helps in better understanding of pharmacology. Due to various reasons, we were unable to arrange for field visits for this group of students. It was observed that the awareness of preclinical studies and clinical trials among medical students was less. ${ }^{24}$ Apart from CMEs and symposiums, field visits to clinical research organizations is one of the ways that bridge the gaps in clinical research in medical students. ${ }^{25}$ Our institute has worked on the feasibility of taking students to industrial visits and made a proposal to implement it in the curriculum from the next batch of II MBBS students. Doctors working in pharmaceutical industry and clinical research organizations companies are key components in the successful development of new diagnostic and therapeutic developments. They have a high level of responsibility for the safe performance of clinical studies and for evaluating the efficacy of new potential treatments in patients. ${ }^{26}$ Exposure of undergraduate medical students to such research organizations might encourage them to learn about the various aspects involved in development of newer therapeutic modalities and diagnostic procedures.

This study has certain limitations that it was conducted in a single institute. Conclusions are mainly focused on students' feedback of various TL methodologies. In addition, questionnaires were only validated for content by local experts and not externally validated.

\section{CONCLUSION}

Students are the best judges to evaluate the effectiveness of various TL methodologies. Feedback from students serves as an effective tool to study the need for modifications in the curriculum. Results from the present study has helped us to make necessary decisions in TL methodologies and evaluation methods to best suit the students. The important aspects emphasized from this study is - to incorporate practical demonstrations of various clinical pharmacology exercises, to increase the frequency of periodic evaluation of students, to make student-led seminars more interactive by including various modifications to them, to continue the ongoing integrated sessions and to include pharmaceutical industrial visit in curriculum.

\section{ACKNOWLEDGMENTS}

Authors would like to acknowledge all the first batch of second MBBS students of the institute who volunteered and actively participation in the study.

Funding: No funding sources

Conflict of interest: None declared

Ethical approval: The study was approved by the Institutional Ethics Committee

\section{REFERENCES}

1. Vasundara K, Kanchan P, Pundarikaksha HP, Girish $\mathrm{K}$, Prassana S, Jyothi R. An imperative need to change pharmacology curriculum: A pilot survey. Indian J Pharmacol. 2010 Dec;42(6):420.

2. Desai M. Changing face of pharmacology practicals for medical undergraduates. Indian $\mathrm{J}$ Pharmacol. 2009 Aug;41(4):151-2.

3. Medical Council of India Regulations on Graduate Medical Education, 2012. [cited 2017 Apr 26]. Available from: http://www.mciindia.org

4. Dagenais ME, Hawley D, Lund JP. Assessing the effectiveness of a new curriculum: Part I. J Dent Educ. 2003 Jan;67(1):47-54.

5. Badyal DK, Bala S, Kathuria P. Student evaluation of teaching and assessment methods in pharmacology. Indian J Pharmacol. 2010 Apr;42(2):87-9.

6. Bhosale UA, Yegnanarayan R, Yadav GE. Attitude, perception and feedback of second year medical students on teaching-learning methodology and evaluation methods in pharmacology: A questionnaire-based study. Niger Med J J Niger Med Assoc. 2013 Jan;54(1):33-9.

7. Chavda N, Yadav P, Karan J, Kantharia N. Second MBBS medical student's feedback on teaching methodology and evaluation methods in pharmacology. Natl J Physiol Pharm Pharmacol. 2011;1(1):23.

8. Zaman SU, Beedimani RS, Pavani ANT, Kumar KS. Feedback of second-year medical students' towards teaching/learning of pharmacology in a private medical college of India. Int J Basic Clin Pharmacol. 2017 Jan 10;5(5):2086-93.

9. Sim SM. Teaching of pharmacology in Universiti Malaya and the other medical schools in Malaysia -a historical perspective. Acta Pharmacol Sin. 2004 Sep;25(9):1209-19.

10. Shenfield GM. Integrating clinical pharmacology teaching with general practice. Br J Clin Pharmacol. 1998 Apr;45(4):399-401.

11. Santra R, Pramanik S, Mandal A, Sengupta P, Das N, Raychaudhuri P. A Study on the Performance of 
Medical Students in Internal Assessment and its Correlates to Final Examinations of 2(nd) MBBS Pharmacology Curriculum in a Medical College of Eastern India. J Clin Diagn Res JCDR. 2014 Dec;8(12):HC01-02.

12. Dhasmana DC, Bala S, Sharma R, Sharma T, Kohli $\mathrm{S}$, Aggarwal $\mathrm{N}$, et al. Introducing structured viva voce examination in medical undergraduate pharmacology: A pilot study. Indian J Pharmacol. 2016 Oct;48(1):S52-6.

13. Naeem SS, Rizvi W, Kumar A. Revisiting undergraduate practical pharmacology. J Pharmacol Pharmacother. 2012 Jan;3(1):76-9.

14. John LJ. A review of computer assisted learning in medical undergraduates. J Pharmacol Pharmacother. 2013 Apr;4(2):86-90.

15. Akat PB, Karande VB, Murthy MB, Burute SR. Interns opinion on bedside pharmacology clinics and its incorporation in undergraduate curriculum. J Pharmacol Pharmacother. 2012 Jan;3(1):56-8.

16. Gomathi KG, Shaafie IA, Venkatramana M. StudentLed Seminars as a teaching-learning method effectiveness of a modified format. South East Asian J Med Educ. 2014;8(1):82-4.

17. Rao BB, Kate V. Problem solving interactive clinical seminars for undergraduates. $\mathrm{J}$ Pharmacol Pharmacother. 2012 Apr;3(2):205-6.

18. Jaarsma ADC, Dolmans DDHJM, Muijtjens AMM, Boerboom TTB, van Beukelen P, Scherpbier AJJA. Students' and teachers' perceived and actual verbal interactions in seminar groups. Med Educ. 2009 Apr;43(4):368-76.

19. Palappallil DS, Sushama J, Ramnath SN. Effectiveness of modified seminars as a teaching- learning method in pharmacology. Int $\mathrm{J}$ Appl Basic Med Res. 2016 Sep;6(3):195-200.

20. Irby DM, Wilkerson L. Educational innovations in academic medicine and environmental trends. J Gen Intern Med. 2003 May;18(5):370-6.

21. Jamkar A, Yemul V, Singh G. Integrated teaching programme with student-centred case-based learning. Med Educ. 2006 May;40(5):466-7.

22. Yadav PP, Chaudhary M, Patel J, Shah A, Kantharia ND. Effectiveness of integrated teaching module in pharmacology among medical undergraduates. Int $\mathbf{J}$ Appl Basic Med Res. 2016 Sep;6(3):215-9.

23. Deb T, Chakrabarti A, Singh R. Does partially integrated learning program help students learn better: A quasi-experimental study in pharmacology. J Pharmacol Pharmacother. 2013 Oct;4(4):282-3.

24. Kiruthika S, Vijayalakshmi S, Geetha KM, Parameswari RM. A Study to Assess the Knowledge of Medical Students on Clinical Trials in Madurai Medical College. Int J Sci Res. 2016 Jul;5(7):892-4.

25. Deo M. Undergraduate medical students' research in India. J Postgrad Med. 2008;54(3):176-9.

26. Heinemann L, Hompesch M. Role of physicians in the pharmaceutical industry and clinical research organizations: take more pride in your work. J Diabetes Sci Technol. 2008 Jul;2(4):707-9.

Cite this article as: Konda VCR, Prakash GB, Subash KR, Rao KU. Second year medical students' feedback on teaching-learning methodologies and evaluation methods in Pharmacology: a questionnaire based study. Int J Basic Clin Pharmacol 2017;6:1311-6. 